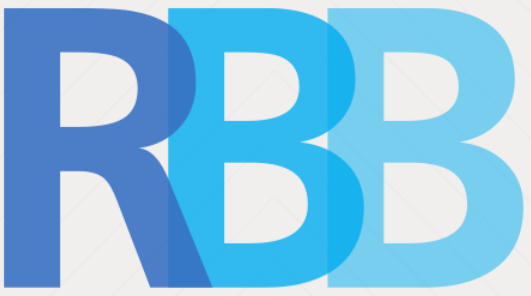

Revista Brasileira de Bioética

Ivone Laurentino dos Santos Secretaria de Estado de Educação, Brasília, DF, Brasil

laurensantos@globo.com

\section{Violência, Poder e Resistência: análises bioéticas à luz da fenomenologia}

\author{
Violence, Power and Resistance: bioethics analysis in the light of \\ Phenomenology
}

Resumo: Este artigo analisa, no contexto da bioética, as relações existentes entre violência, poder e resistência, à luz da fenomenologia. A perspectiva é de resgatar a Bioética, no sentido de repensarmos as práticas sociais, quando estas se omitem frente à violência e a todo tipo de objetivação dos seres humanos. Devido a complexidade da problemática em questão, o método foi o fenomenológico, na tentativa de ver a essência da realidade mesma, evitando as explicações fáceis do senso comum. A aceitação tácita da violência, por parte de setores sociais importantes, acaba por provocar a 'banalização' deste e de outros problemas que afetam, especialmente, a 'banda frágil da sociedade'. Este 'silêncio' deve ser rompido, possibilitando a resistência às forças políticas que atuam contra as liberdades individuais e a democracia. É imprescindível, nesse contexto, que a bioética promova os processos de desnaturalização de males sociais - como a violência - que diminuem, significativamente, as chances de vida das pessoas mais vulneráveis.

Palavras-chave: bioética, poder, violência, resistência, fenomenologia.

Abstract: This article analyzes, in the context of bioethics, the existing relationships between violence, power and resistance, in the light of phenomenology. The perspective is of revisits Bioethics as a way of rethinking social practices at a time when these are confronted by violence and all kinds of objectivization of human beings. Given the complex nature of the topic, the phenomenological method of enquiry was used, in order to understand the essence of reality while avoiding cursory explanations. The tacit acceptance of violence by key social sectors leads to the 'trivialization' of violence and other problems that especially affect the most vulnerable sectors of society. It is clear that we need to focus on counteracting the 'silence' displayed by hegemonic bioethics and resist the forces that militate against democracy and individual freedoms. In this context, it is essential to use bioethics to counter violence and other social evils liable to undermine the lives of society's weaker members.

Keywords: bioethics, power, violence, resistance, phenomenology. 


\section{Introdução}

A violência foi um grande marco para o século XX. Guerras e bombas nucleares já na primeira metade do século; conflitos no Oriente Médio; guerras civis na África; uma guerra no leste da Europa: barbárie e genocídio em plena década de 1990. O século XXI não tem sido muito diferente: o 11 de Setembro de 2001 não deixou dúvidas de que os conflitos se intensificaram nos últimos anos. No Brasil, a cidade emblemática, quando se trata de violência, é o Rio de Janeiro, onde intensificaram-se, ainda mais, os problemas de segurança pública devido às já tão conhecidas situações conflituosas vivenciadas pela população carioca, com destaque para o tráfico nas favelas. Em São Paulo, ações do PCC (Primeiro Comando da Capital) seguem afetando o dia a dia dos moradores da cidade: insegurança, medo, mortes, assaltos frequentes à comércios e bancos, escolas e universidades fechadas, prováveis alvos dos ataques. Enfim, o que diz a realidade mesma (Dartigues, 1992; Heidegger, 2015), no que se refere à violência? Como compreender o contexto de conflitos e tensões permanentes em que vivemos, sem negar a sua complexidade? Frente à essa realidade, o que nos espera e quais as perspectivas para as gerações futuras? E ainda: e a bioética, como ética aplicada à vida, o que tem a dizer sobre a escalada da violência no país (Ipea, 2019)?

No campo da bioética, responsabilizar-se e comprometer-se torna-se inevitável. Trata-se de uma área de saber que vem passando por uma ampliação conceitual, nos últimos anos, e que, nos dias atuais, não se furta a pensar as questões que afetam as pessoas, nas suas existências concretas, em sociedade, dentre elas, a violência, que a despeito das vozes que teimam em banalizá-la (Arendt,1999; Souki,2006), emerge como um problema persistente (Garrafa, 2005a), devendo ser pensado, com o máximo de urgência, sem perder de vista seu caráter complexo e mobilizador.

A questão fundamental é que problemas sociais, de tamanha gravidade, como a violência, evidenciam a urgência de fortalecimento e compreensão de uma bioética que, nos moldes da Bioética de Intervenção (Garrafa,2005a/2005b), seja capaz de romper com determinadas barreiras academicistas, na medida em que reconheça a necessidade de construir uma nova realidade social, que atenda os interesses da maioria das pessoas, especialmente, dos 'excluídos sociais', desamparados pela ideologia de mercado (Porto \&Garrafa, 2005). 
Faz-se necessário, portanto, romper os limites cartesianos que circunscrevem os saberes à campos específicos, gerando conhecimentos que ultrapassem determinados limites disciplinares e que, portanto, sejam capazes de responder às transformações da realidade, o que justifica a opção, nesse texto, de colocar em destaque a Bioética de Intervenção (Garrafa, 2005a), haja vista que esta abordagem teórica - há anos trabalhada pela Cátedra UNESCO de Bioética da Universidade de Brasília - nos possibilita tratar, com a devida importância, o fenômeno da violência, demonstrando, dentre outros aspectos, as relações deste com as políticas de Governo (ou ausência delas), que, muitas das vezes, tem funcionado como combustíveis para o fortalecimento do desrespeito aos direitos humanos e à dignidade humana.

A defesa da vida, com o mínimo de dignidade para todos, torna-se ainda mais complexa, devido ao contexto de extrema intolerância em que vivemos hoje no Brasil, onde premissas fundamentais para o Estado Democrático de Direito (Brasil:CF,1988) como, por exemplo, a liberdade de expressão, tem sido fortemente ameaçadas. Somente uma discussão aberta, amparada por uma bioética politizada, inclusiva, plural (Garrafa,2005a, 2005b)) e atenta aos sentidos construídos pelas pessoas, em suas realidades concretas (Merleau-Ponty, 1999) pode dar conta de tamanha complexidade. A questão fundamental é a ousadia de pensar, com radicalidade, as relações de poder, tanto das situações cotidianas da realidade mesma, como do contexto macro das sociedades contemporâneas, Em síntese, pensar a existência multifacetada do fenômeno violência, implica na decisão de considerar todas as possibilidades de intervenção (Garrafa,2005), no sentido de resgatar, com o máximo de urgência, liberdade e dignidade, para um grande número de pessoas, que vivem sujeitas a degradação e a miséria, em grande parte, por conta da violência.

A perspectiva deve ser, portanto, de provocar o diálogo necessário à produção coletiva de mecanismos éticos, capazes de neutralizar a violência e favorecer, de modo significativo, a política como expressão da liberdade (Arendt, 2015), pautada no respeito à todos os humanos, sem restrição de cor, raça, sexo ou religião, como preconiza a Declaração Sobre Bioética e Direitos Humanos da UNESCO, DUBDH (UNESCO, 2005). O que dificulta bastante o combate da violência no Brasil é que setores importantes da sociedade brasileira, parecem anestesiados, apáticos, indiferentes, quando consideramos a gravidade do problema da violência no país (Ipea, 2019). Talvez o que parece ser uma 'aceitação tácita da violência' decorra do fato de que esta atinge, com mais força, os mais frágeis e vulneráveis e, como tal, desperta pouco ou nenhum interesse das autoridades constituídas na busca de soluções. 
Por outro lado, a violência vem acumulando tantas vítimas e com tamanha frequência, que o problema tende a ser visto como insolúvel e, desse modo, acaba por se transformar em algo corriqueiro, o que contribui, não somente para a sua própria naturalização e banalização(Arendt,1999; Souki,2006), como para um espécie de 'aceitação tácita' de todas as problemáticas sociais que a envolve. Esse processo de naturalização dos problemas sociais, como a violência, a fome, a miséria etc. acaba por prejudicar, sobremaneira, uma possível mobilização e transformação da realidade. Questão que não quer calar: as milhares de vidas ceifadas pela violência, inclusive dos jovens, são irreparáveis, mas o que tem sido feito, de modo preventivo, pelo Estado e pela sociedade, como um todo, ao menos no sentido de amenizar os danos futuros? Com o avanço no Brasil, das políticas neoliberais, e a consequente defesa do Estado mínimo, resta à cada cidadão e cidadã brasileiros se conformar em viver em constante risco, torcendo para que os eventos de violência não batam às sua porta, ou, resistir na luta para que seu direito à segurança e a qualidade de vida deste decorrente, sejam respeitados.

A expectativa é que este texto possa contribuir para intensificar o debate necessário sobre a violência, desnudando as suas variadas causas, bem como seus efeitos nefastos, especialmente nas vidas daqueles que pertencem à banda frágil da sociedade (Garrafa, 2001a). Assim, a perspectiva foi de que, amparados pelo método fenomenológico (Dartigues, 1992; Merleau-Ponty, 1999; Heidegger, 2015), que recusa as explicações fáceis do senso comum para os fenômenos sociais, tratemos, com a devida urgência, o fenômeno violência, até então negligenciado pela bioética hegemônica principialista (Beauchamp \& Childress, 2002).

A opção desse texto de recorrer ao método fenomenológico, se dá devido a crença de que tal método dar conta de pensar a violência, com a radicalidade que se faz necessária. Um dos princípios basilares do método fenomenológico é "zu den Sachen selbst zurück", o que significa 'um retorno às coisas mesmas' (Dartigues, 1992). Isso implica em não ter verdades prévias ou preconcebidas que acompanhem e determinem o encontro do pesquisador com o fenômeno em análise.

Aprender fenomenologia é aprender ou reaprender a ver; trata-se de se fazer um esforço de 'mirada'. Nesse contexto, a fenomenologia abre a possibilidade do pesquisador aprender a ver a realidade sem filtros, ou, dito de outro modo, sem mensageiros intermediários (Heidegger, 2007). A fenomenologia se refere, portanto, a uma 
orientação, para que o pesquisador volte sua atenção para os fenômenos como eles se manifestam, em si mesmos (Merleau-Ponty, 1999).

Esse princípio fundante da Fenomenologia norteou a escrita desse texto, no sentido de que toda a atenção foi concentrada na violência, como ela se apresenta, sem subterfúgios de nenhuma espécie. Esse princípio de investigação, como diz Heidegger (2007) é a via por onde se alcança o campo de estudo, o caminho por onde se cria a mirada ou desde a qual o assunto será investigado; caminho este definidor do modo como se pretende desenvolver o fenômeno ou a forma de tratá-lo (Heidegger, 2007).

Por outro lado, esse caminho, que pode ser compreendido como uma espécie de fio condutor da pesquisa, não deve ter a pretensão de esgotar resultados, teses ou até dogmas extraídos dos conteúdos do objeto a ser conhecido, sendo apenas e tão somente a direção que orienta a busca pelo saber (Heidegger, 2007). No decorrer do texto que segue, a pretensão é que os leitores percebam que a fenomenologia, aqui em questão, é menos reflexiva, nos moldes de Husserl (2005), e mais de acordo com a fenomenologia hermenêutica, de Heiddeger $(2007,2015)$, isso devido as dificuldades encontradas pela autora para suspender, mesmo que provisoriamente, o mundo onde estão inscritos o poder e a violência, em prol de um reencontro futuro.

Ao contrário, a aposta desse texto foi na possibilidade de, amparada em Heidegger $(2007,2015)$ investir no acesso direto ao fenômeno violência, naquilo que ele é; dando um mergulho para experimentá-lo, em algumas das suas diversas nuances e possibilidades. Espero que a estratégia metodológica funcione, a ponto desse texto contribuir para que se rompa este incômodo 'silêncio' sobre a violência, possibilitando que o debate sobre este fenômeno social, relacionado as vida e as mortes das pessoas, especialmente daquelas que pertencem à parcela mais pobre da população brasileira, seja retomado, com toda a intensidade e complexidade que o tema exige.

O debate sobre o contexto violento em que as pessoas socialmente mais frágeis, se encontram, deve ser encarado com a devida seriedade, tendo em vista o papel que a própria bioética deve desempenhar junto às políticas econômicas, no sentido de alertar a população da necessidade de prevenir e combater a violência. Por conta disso, e também no sentido de fazer um alerta para os males gerados por um Estado, que não age propositivamente frente à vulnerabilidade e à violência, o texto em questão dedica o último tópico à pensar as possibilidades concretas de uma 
bioética, que amplie as nossas possibilidades de resistência à violência, a partir das contribuições de dois grandes nomes da filosofia contemporânea: Hannah Arendt (2009a) e Michel Foucault (2001a).

\section{A violência como uma questão (bio)ética}

Uma simples leitura sobre a violência evidencia a precariedade de estudos sobre as relações existentes entre este fenômeno social e a bioética. Isso não se justifica, se partirmos do pressuposto de que a violência é um problema de saúde pública (Barchifontaine \& Pessini, 1989), não no sentido restrito do termo 'saúde', mas numa visão ampliada de saúde, como qualidade de vida. A violência, não somente interfere nas condições de vida dos cidadãos, como é causa determinante de morbimortalidade (Ipea, 2019), especialmente, entre os mais pobres.

As problemáticas relativas à todas as questões éticas que dizem respeito à vida e à saúde - incluindo a violência - carecem, portanto, de uma abordagem interdisciplinar, à luz de uma (bio)ética social, comprometida com a transformação social (Garrafa,2005a, 2005b), que dê conta de suas complexidades. O caráter complexo, inerente aos fenômenos sociais e, em particular, a violência, pode ser detectado em sua origem, manifestações e efeitos, na medida em que gera perdas irreparáveis.

Estimativas feitas pelo Atlas da Violência (Ipea, 2019) mostram que os prejuízos do Brasil com a violência chegam, por ano, a $6 \%$ do PIB (Produto Interno Bruto), o que equivale a, aproximadamente, $\mathrm{R} \$ 373$ bilhões, considerando valores de 2016 . O valor corresponde ao investido pelo Estado brasileiro em educação. Trata-se, portanto, de um quadro bastante grave, que carece de toda atenção da sociedade, como um todo, e, em especial, do poder público.

A violência, em todo o seu polimorfismo, tem sido, de certo modo, discutida pela sociedade, pela mídia, pelos cientistas sociais e por outros segmentos do saber. Entretanto, se no âmbito geral a discussão é precária, na bioética, tal questão tem sido abordada, de forma ainda mais insuficiente, o que deixa uma indagação a ser respondida: Por que a violência, fenômeno relacionado com o campo da saúde coletiva, não consta da pauta de prioridades da bioética tradicional? Analisando essa questão, o fato é que esses dois campos de conhecimento, a saúde coletiva e a bioética, estiveram isolados um do outro, embora percebamos uma aproximação e um reconhe- 
cimento de que tais perspectivas devem ser integradas, para abordar os complexos aspectos de que se reveste a saúde humana.

Ambos os campos, saúde pública e bioética, são interdisciplinares (Fortes \& Zoboli, 2003) e a bioética, há alguns anos, em função do diálogo entre diferentes especialistas, vem propiciando a incorporação de temas não enfocados no início. Isto implicou num avanço de uma ética biomédica para uma bioética global, sendo a segunda, proposta pelo Potter (2016) - um dos precursores da bioética- incapaz de assumir uma postura neutra e asséptica frente aos problemas sociais graves como miséria, fome, violência etc. problemas estes que persistem em existir em pleno Séc. XXI (Garrafa \& Costa, 2000). Uma bioética global (Potter, 2016) não se furta à pensar mecanismos éticos capazes de intervir na realidade social, de modo a contribuir para, no mínimo, amenizar os efeitos nefastos da 'banalização deste mal'(Arendt,1999; Souki,1998), que, sem dúvida, é um dos mais preocupantes e desafiadores para todos nós: a violência.

Isso quer dizer que, nessa perspectiva, torna-se inviável falar em princípios como autonomia, beneficência e não-maleficência, quando a injustiça social bate às portas de ricos e pobres. Injustiça social que, diga-se de passagem, descamba em violência e degradação humana (Garrafa \& Pessini, 2003; Almeida et al, 2006). Dessa forma, o princípio da justiça assume papel fundamental dentro da bioética, e isto pode ser verificado pela ênfase em se buscar uma bioética interventiva e libertadora (Garrafa, 2005b), isto é, uma bioética social com ênfase, por um lado, no bem-estar e na justiça social mais que em direitos individuais ou virtudes pessoais (Garrafa \& Pessini, 2003), e, por outro lado, na relação entre os direitos humanos e a bioética (Oliveira,2011).

Os direitos humanos que, no início, eram estranhos aos problemas éticos suscitados pelas ciências e pelas técnicas, hoje estão bem próximos da bioética, devido o reconhecimento de que se trata de áreas que defendem os mesmos interesses (Oliveira, 2011). Enfim, tendo como base a perspectiva de uma bioética global (Potter, 2016), voltada para a concretização da justiça e o fortalecimento da dignidade humana, torna-se imprescindível que a bioética, numa perspectiva globalizante (jamais globalizada) e interdisciplinar, assuma para si, a tarefa de promover o diálogo entre estes grandes temas da ética social: poder, violência e direitos humanos.

\section{As possibilidades de uma bioética interventiva no com- bate e na prevenção da violência}

A bioética não deve, em nenhuma hipótese, se eximir da tarefa de pensar mecanismos éticos de intervenção, adequados para o enfrentamento do grave qua- 
dro de 'banalização da violência' (Arendt,1999; Souki,1998) em que nós, brasileiros, nos encontramos; quadro este que tem resultado na constante desvalorização da dignidade e integridade dos seres humanos, especialmente daqueles cidadãos com baixo poder aquisitivo. É urgente, portanto que façamos a reflexão sobre o fenômeno da violência hodierna, que se dissemina assumindo características nítidas de banalização e naturalização, comprometendo, desse modo, as lutas e movimentos sociais pela dignidade da vida humana, tida como um valor exponencial.

Torna-se necessário, portanto, que façamos na bioética, o debate sobre a violência, não somente evidenciando os dilemas éticos que lhe são inerentes, mas, principalmente, pensando sobre quais seriam as possibilidades desta área de saber de, ao menos, minimizá-los. Trata-se de um desafio de extrema complexidade, para todos nós, brasileiros, uma vez que estamos todos imersos em um ambiente violento, assumirmos e nos comprometermos politicamente com a tarefa de contribuir para a (re)construção da nossa dignidade, como Nação, a partir de noções bioéticas e de suas relações com os direitos humanos universais.

O que está em questão, quando se trata da violência é o mais valioso de todos os direitos humanos: o direito à vida, que somente será respeitado, quando o Estado brasileiro, em conexão com os diversos setores da sociedade, assumam a decisão política de tirar do papel o direito constitucional de cada brasileiro ou brasileira à saúde e segurança, Ihes garantindo não apenas estender suas existências, mas acrescentar qualidade de vida, aos anos que lhes restam.

Para Garrafa (2003), a partir do momento em que a bioética, como 'ética aplicada' ganhou uma maior visibilidade, mas, especificamente, nas últimas décadas do Século $X X$, tem havido um maior reconhecimento da referida disciplina. $O$ fato é que o contexto complexo de um novo tempo histórico, pautado em uma pluralidade cultural e 'evolução' dos costumes, passou a exigir mais das sociedades, no sentido de ter que pensar novos padrões morais referenciais, que desse conta das questões que emergiam na sociedade.

Assim sendo, pessoas e grupos humanos passaram a mudar os princípios e valores que estabeleciam a rota básica para suas decisões e comportamentos, tanto no âmbito privado como no público. Tais transformações, verificadas na estrutura da moralidade social, decorreram no fato de que os aspectos éticos deixaram de ser considerados como elementos de índole superestrutural, para ter participação direta 
e concreta nas decisões relacionadas com a vida, não somente das pessoas, mas também nas sociedades e até das nações (Garrafa,2003).

Segundo Costa (2001) a bioética faz parte de um projeto de tolerância na diversidade. Com o reconhecimento da pluralidade moral da humanidade, tornou-se imperativa e urgente a estruturação de uma disciplina, nos moldes da bioética, que mediasse os conflitos cotidianos, para além daqueles comuns à prática médica. Nessa perspectiva, as possíveis respostas aos conflitos serão resultantes do próprio desenrolar da história moral das sociedades e dos indivíduos, o que sinaliza a existência, não de uma bioética, mas de várias bioéticas, à depender das necessidades postas pelas pessoas, nas suas realidades concretas ou em seus contextos de vida.

Desse modo, Garrafa (2003) constata que, neste início de Século XXI, a ética adquiriu identidade pública, ou seja, deixou de ser considerada como uma questão abstrata e de consciência à ser decidida na esfera da autonomia, especialmente uma autonomia pensada em termos principialistas (Beauchamp \& Childress, 2002), passando a extrapolar o foro individual, íntimo e pessoal. Hoje, a bioética, numa visão política, libertária e interventiva (Garrafa, 2005a), dá mais ênfase à análise das responsabilidades sociais, seja na priorização de ações ou até na formação de pessoal capacitado para debater os temas de relevância social.

Nesse contexto, a perspectiva é de se demonstrar o caráter essencial e urgente de se pensar, no âmbito da coletividade, formas de intervenção pública à serem programadas, mediante problemas que diminuem as chances de vida, especialmente dos excluídos sociais. Surge, portanto, como alternativa à bioética tradicional, uma bioética menos voltada para a disseminação de princípios éticos 'elevados' e distantes, da realidade concreta (Merleau-Ponty, 1999), da grande maioria dos brasileiros, e mais comprometida com a análise, a discussão e o desenvolvimento de mecanismos éticos de intervenção, que possam ser utilizados no enfrentamento dos conflitos, da violência, da desigualdade social e da extrema pobreza, que marcam os países periféricos, ainda em desenvolvimento (Garrafa, 2005a).

Mas ainda há um longo caminho pela frente. Segundo Garrafa (2003) o que está acontecendo, muitas vezes, é a utilização da justificativa ética como ferramenta, como um instrumento metodológico neutro, destinado à exclusiva leitura e interpretação horizontal e neutra dos conflitos morais e sociais, por mais dramáticos que estes sejam, o que tem resultado numa ética asséptica, amenizada frente à gravidade das 
diferentes situações, principalmente aquelas coletivas e que, portanto, acarretam as mais profundas violências, distorções e injustiças sociais.

Para Garrafa (2003) a compreensão do que se denomina bioética, neste inicio de Século XXI, varia de um contexto a outro, de uma nação a outra e, inclusive, entre diferentes estudiosos do tema, em um mesmo país, em parte, pelas diversas mudanças pelas quais tal disciplina tem passado desde os anos 70. A bioética é uma área de saber nova; que somente a partir dos anos 2000 - em função da Declaração Universal sobre Bioética e Direitos Humanos (DUBDH) - passou a ter uma linguagem teórico-metodológica mais adequada e pertinente para a compreensão, não somente dos problemas sociais emergentes, como também daquelas questões persistentes ou cotidianas: violência, exclusão social, saúde, discriminação etc., enfrentadas pelas sociedades contemporâneas e que já deveriam, há muito tempo, terem sido superadas.

No caso específico do Brasil e demais países latino-americanos, é imprescindível uma grande discussão sobre a bioética, que passe a ser incorporada ao próprio funcionamento dos sistemas públicos de saúde (Giovanella et al., 2012), o que, sem dúvidas impactaria na violência, aqui entendida como um problema de saúde pública, o que nos remete a algumas questões fundamentais: Afinal, no que se refere a saúde pública, qual é a responsabilidade social do Estado? quais deveriam ser os critérios na definição de objetivos relacionados com a priorização, alocação, distribuição e controle dos recursos? E quanto à gestão do sistema de saúde? Como garantir a participação da população de modo organizado e crítico? (Garrafa, 2005a, 2005b).

Vivemos, em tese, em um Estado Democrático de Direito, mas, na prática, o Estado brasileiro parece ignorar as necessidades dos cidadãos. Resta-nos, portanto, contribuir para a melhoria do funcionamento do sistema de saúde - saúde aqui entendida como qualidade de vida - como um todo, nesse sentido, vale destacar a importância da DUBDH (UNESCO, 2005: 10), no seu artigo 14, quando preconiza "(...) (iii) a melhoria das condições de vida e do meio ambiente; (iv) a eliminação da marginalização e da exclusão de indivíduos por qualquer que seja o motivo e a redução da pobreza e do analfabetismo, onde fica explicitada a preocupação com questões que tem sido determinantes para a escalada da violência no Brasil.

A sugestão, portanto, é que a DUBDH (UNESCO, 2005), em função do seu caráter de complementaridade entre os seus Princípios (UNESCO, Art. 26:14) deva ser analisada, no sentido de que a mesma possa ser um instrumento ético importante nas lutas pelos direitos humanos universais. No que se refere, em particular, ao ne- 
cessário resgate da paz, a Declaração contém - em todo corpo do texto, elementos importantes, no sentido de afirmar uma 'ética interventiva', comprometida com os problemas de seu tempo e, portanto, com o combate à todo e qualquer tipo de violência e toda e qualquer forma de discriminação.

Segundo Garrafa (2005a, 2005b), dentro do âmbito social do documento, existem diversos pontos que guardam relação direta ou indireta com o tema dos Desafios éticos para o Séc. XXI, dentre eles, se pode mencionar os seus objetivos, apontados nos seus Artigos. Em síntese, a Declaração reitera a necessidade de 'promover o respeito da dignidade e proteger os direitos humanos, velando pelo respeito às vidas dos seres humanos e às suas liberdades fundamentais, de acordo com o direito internacional relativo aos direitos humanos'.

Também fazem parte da DUBDH (UNESCO, 2005) artigos relacionados a temáticas sociais importantes, tais como, 'Respeitar à vulnerabilidade humana e à integridade pessoal'; 'Igualdade, justiça e equidade'; 'Não discriminar e não estigmatizar', além de princípios importantes como 'Solidariedade e cooperação', temas indispensáveis quando pensamos na prevenção, combate e superação de graves problemas sociais como a violência, tema aqui em questão.

\section{A (bio)ética como forma de resistência e luta em Arendt e Foucault}

Numa perspectiva de uma ética social fenomenológica e interventiva (Merleau-Ponty, 1999; Garrafa, 2005a), dois dos filósofos contemporâneos mais adequados no trato das problemáticas relacionadas ao poder e a violência, são Arendt (2009a, 2009b) e Foucault (2001a, 2001b), visto que ambos transcendem as aparências do dito, até então, sobre tais fenômenos. Ambos rompem com as visões tradicionalmente aceitas sobre poder, violência, resistência etc. sinalizando com brilhantismo as 'brechas' do real, que podem ser ocupadas, no sentido de transformação da realidade e superação dos problemas sociais, que diminuem as perspectivas de vida, com qualidade, para uma grande parcela das populações em todo mundo, e, em especialnos países, como o Brasil - ainda marcados pela fome(Castro,1984), desigualdades e iniquidades sociais.

Numa visão ampliada, a bioética, como ética da vida, (Garrafa, 2005b), com pretensões de pensar a realidade concreta, não pode se eximir da tarefa de, numa 
perspectiva inter e multidisciplinar (Garrafa, 2005a/2005b), recorrer à saberes outros, que deem conta de instrumentalizá-la, na busca de soluções para os problemas que afligem, de forma mais impactante, os países em desenvolvimento, como o Brasil. Nesse contexto, filósofos como Hannah Arendt (2009a, 2009b) e Michel Foucault (2001a,2001b), desde que interpretados de modo crítico, são imprescindíveis para a compreensão de fenômenos como poder e violência e suas implicações nos tempos difíceis em que vivemos.

O Poder, para Arendt (2009a), diz respeito à habilidade humana, não somente para agir, mas para agir em comum acordo ou, para usar o termo da filósofa, para agir em concerto. Dessa forma, o poder é sempre fruto da ação coletiva. O poder emerge onde quer que as pessoas se unam e ajam em concerto, não sendo jamais propriedade de um indivíduo; haja vista que pertence à um grupo e permanece em existência, apenas na medida em que o grupo continua unido. Está no poder, portanto, significa ter sido empossado por um número de pessoas para agir em seu nome. Para Arendt (2009a), o poder - ação política - é um fim em si mesmo e, dessa forma, não pode ser instrumentalizado em nome de qualquer outro fim; considerando que o sentido último da ação política é sempre a interação entre os homens, o poder não pode ser avaliado pelo seu resultado final, mas valorizado por si mesmo (Arendt, 1993).

Mas, sendo o poder resultante de uma ação coletiva, o que seria a violência? Um aspecto importante da contribuição de Arendt (2009a, 2009b) para a reflexão sobre a violência é sua delimitação conceitual, num campo bem afeito a muitas implicações e confusões. Na perspectiva da autora é fundamental distinguir, não apenas poder e violência, como autoridade e força, poder e vigor, visto que os mesmos se referem à fenômenos distintos e diferentes. Enquanto a Autoridade, para Arendt (2009a) caracteriza-se pelo reconhecimento inquestionável à quem se obedece, a Violência tem um caráter instrumental e se expressa no uso de meios, implementos, instrumentos, ferramentas pelos quais a violência é exercida. Nesse sentido, a violência é sempre uma reação ao enfraquecimento do poder; é o agir sem argumentar, sem o discurso. A violência é sem justificativas, sem argumentos, sem um processo discursivo, que é a essência de todo poder.

E o que isso nos diz sobre a bioética? Uma bioética comprometida com a realidade social e política, que definem as vidas e as mortes de milhares de pessoas, poderia atuar no sentido de ocupar os espaços democráticos de debates, de diálogos, de modo que a violência não seja sequer vista como uma possibilidade. Se a violência, 
como diz Arendt (2009a) resulta do enfraquecimento do poder, talvez, a saída seja agir de modo a empoderar os cidadãos e cidadãs, para que, possam agir, em conjunto e, de modo preventivo, contra a violência, combatendo-a e superando-a. Quando os direitos fundamentais estão em risco, o problema passa a ser de todos e a luta pela garantia desses e de outros tantos direitos também.

A autora deste texto concorda com Arendt,(2009a) quando ela afirma o poder como algo que só se efetiva quando as palavras fazem sentido e os atos não são brutais, quando as palavras não são empregadas para dissimular intenções, mas para revelar ou desvelar realidades. Conclui-se, nesse caso, que se os atos não são usados para violar e destruir, mas, ao contrário, para criar relações e novas possibilidades; a bioética, com pretensões interventivas e libertárias (Garrafa, 2005a; Garrafa, 2005b), poderia contribuir para o fortalecimento de uma democracia, em que fosse, cada vez mais, improvável os pensamentos totalitários (Arendt,2012) e antidemocráticos, geradores de violência.

Arendt (2009a) define a violência como o agir sem argumentar e o império do silêncio; por conta disso, onde quer que a violência domine de forma absoluta, como por exemplo, nos campos de concentração dos regimes totalitários, não apenas as leis - les lois se taisent - mas tudo e todos devem permanecer no mais absoluto silêncio (Arendt,2012). A bioética, portanto, pode e deve contribuir para a construção de mecanismos éticos, com potencial para romper esses 'silêncios' impostos pela presença maciça da violência.

Dito de outro modo, uma bioética interventiva pode encontrar, na perspectiva política de Arendt (2009a, 2009b), uma parceria bem interessante, visto que para a filósofa, a pura violência é muda, a bioética poderia contribuir no sentido de provocar bastante 'barulho', subvertendo a 'ordem' posta pela violência. Se a violência pode ser compreendida como uma forma de expressão dos que não têm acesso à palavra; a saída talvez seja dar voz, através do diálogo bioético, para os aprisionados pelo ciclo vicioso da violência, que, emudecidos pela força, são levados também a praticar a violência, visto que esta passa a ser a alternativa que resta. Quanto aos déspotas que desconhecem, por variados motivos, outro recurso, senão a violência -, o poder, que para Arendt (2009a), é ação em concerto, seria um antídoto importante no combate às suas atitudes antidemocráticas.

O fato é que, se for verdade, como pensa Arendt (2009a, 2009b), que quando a palavra não é possível, a violência se afirma e a condição humana é negada, não ha- 
veria outro caminho para uma bioética, com pretensões libertárias (Garrafa, 2005a), senão tentar reverter o espaço ocupado pela violência, investindo no resgate e na devolução do direito à palavra, pela oportunidade da expressão das necessidades e reivindicações dos sujeitos, pela criação de espaços coletivos de discussão e pela sadia busca do dissenso e da diferença.

Na perspectiva de Arendt (2009a) o poder tece redes e não se focaliza num ponto só, constrói discursos e promove sujeitos sociais; em decorrência, existem distintas formas de poder, não sendo este nem absoluto, nem unívoco, assim como existem também formas de resistência. Em Foucault (2001), contemporâneo de Arendt, o poder também não está localizado em nenhum ponto específico da estrutura social, funcionando como uma rede de dispositivos ou mecanismos aos quais nada e ninguém escapa, aos quais não existe exterior possível, limites ou fronteiras. também em Foucault (2001a) a resistência se faz presente como reação ao poder, poder este que não é de modo algum universal. Quando aparece a resistência, o poder começa a se alterar, se afetar ou se submeter. A bioética como campo interdisciplinar de saber, nos moldes arendtianos e até foucaultianos, teria a possibilidade, portanto, de se configurar como um espaço legítimo de resistência.

Segundo Foucault onde há relações de poder, haverá sempre “(...) uma possibilidade de resistência. Jamais somos aprisionados do poder: podemos sempre modificar sua dominação em condições determinadas e segundo uma estratégia precisa" (2001a, p.241), Para o filósofo, o poder não existe, o que existe são práticas ou relações de poder disseminadas por toda a estrutura social, e, portanto, sempre presentes, que se exercem como uma multiplicidade de relações de forças. Entretanto, se para Foucault (1995:243) "o poder não é da ordem do consentimento; nem renúncia à uma liberdade, transferência de direito, poder de todos e de cada um delegado a alguns [...] a relação de poder não é jamais a manifestação de um consenso", para Arendt(2009a), como vimos, o poder se define como ação em concerto.

A tentativa de Foucault (2001a, 2001b) é de analisar um poder que não é de natureza mecânica. Ou melhor, o filósofo não quer fazer uma análise mecanicista do poder, o que também pode ser bem interessante para a bioética. Para ele, o poder não está contido numa única instituição, muito menos somente no Estado. As argumentações de Arendt (2009a, 2009b) e Foucault (2001a, 2001b) sinalizam que, para nenhum dos dois, ele está associado à relações de força, o que abre a possibilidade de se pensar formas de resistências em ambas as teorias. A resistência à determi- 
nadas forças e violências, em Foucault (2001a), se torna possível, devido ao fato de que o filósofo não considera o poder como uma realidade que possua uma natureza fixa ou imutável, muito menos uma essência definida por características universais, o que o aproxima sobremaneira de uma abordagem fenomenológica (Dartigues, 1992; Merleau-Ponty, 1999) do real.

Se o poder, para Foucault (2001a), não pode ser descrito como objeto natural, uma coisa, mas como uma práxis social constituída na história, e, portanto capaz de ser repensada, reformulada e até substituída pelo novo, também para Arendt (2009a) o poder e a violência jamais seriam fenômenos naturais, pois pertencem ao âmbito político dos negócios humanos, cuja qualidade humana é garantida pela faculdade do homem para agir, bem como a habilidade para começar algo novo. Enfim, tanto Arendt (2009a,2009b) quanto Foucault (2001a, 2001b) descartam as metáforas orgânicas da violência como doença da sociedade, e, desse modo, abrem espaço, cada um a seu modo, para a resistência.

Desnaturalizar o poder, desvelando sua constituição histórica são objetivos presentes tanto em Foucault (2001a, 2001b) como em Arendt (2009a, 2009b), o que aproxima ambos de uma bioética politizada, com pretensões interventivas e libertárias (Garrafa, 2005a). Em sintonia com o processo de desnaturalização, presente na obra foucaultiana, Arendt também contribuiu para despersonificar a violência, uma vez que atribui à ela um caráter apenas instrumental. Nesse contexto, a violência jamais promove causas, acontecimentos, revoluções, progressos, nem retrocessos; podendo servir apenas para dramatizar queixas e demandas, trazendo-as ao conhecimento público. A violência é, nessa perspectiva, reação ao decréscimo do poder e não princípio de ação.

Para Arendt(2009b), a violência torna-se capaz de destruir o poder, mas jamais pode substituí-lo. Nem mesmo poderá reconstruí-lo ou recuperá-lo; ou melhor, a violência não reconstrói dialeticamente o poder, ao contrário, paralisa-o, aniquilando-o (2009a). Talvez essa percepção da instrumentalidade da violência, ao aniquilar e destruir o poder, possa explicar os já mencionados 'silêncios', mesmo em contextos de tamanha gravidade como o quadro crescente de violência em que estamos inseridos. A violência tem alcançado seu objetivo primeiro, emudecendo aqueles que estão sobre o seu domínio.

Enfim, tanto em Foucault (2001a, 2001b), quanto Arendt (2009a, 2009b), a violência perde parte do seu glamour, na medida em que sua existência dependerá 
sempre do enfraquecimento da capacidade humana para resistir aos seus propósitos, ou seja, a violência, nessa perspectiva, não existe em si mesma. Com isso, fica a esperança nada alienante de que uma bioética social libertadora, com pretensões interventivas (Garrafa,2005a/2005b) possa contribuir na criação de mecanismos éticos que funcionem no sentido de neutralizar a violência, dar voz aos emudecidos pelo uso da força, e, desse modo, potencializar as ações dos cidadãos e cidadãs, tendo em vista a necessidade já pontuada por Arendt (2009a, 2009b) de ação em concerto, ação esta que inviabilize as intenções totalitárias e violentas (Arendt,2012) dos antidemocráticos de plantão.

\section{Considerações Finais}

Vivemos tempos tenebrosos, cheios de contradições e paradoxos; de um lado, a produção de tecnologia de ponta, do outro lado, fome, miséria, desigualdade e violência. $O$ fato é que, por conta das escolhas éticas e políticas feitas neste mundo 'tecnologizado', vivemos em situações de fronteira, nas quais em função do poderio econômico das biociências, a democracia tende a se enfraquecer e os problemas sociais, que impactam, especialmente nas vidas dos mais frágeis passam a ser, por um lado, naturalizados pelo senso comum e, por outro lado, negligenciados pelas forças políticas do Estado.

Frente à este quadro, não custa reiterar a necessidade da construção de uma bioética capaz de pensar a si mesma, empreender reflexões sobre os procedimentos técnicos, os fundamentos da atividade científica, sua aplicabilidade e relação com o mercado etc. Somente nestes termos, a bioética se constituirá como uma área de saber, com condições de frear o processo público, notório e contínuo de 'coisificação dos seres humanos', do favorecimento da técnica pela técnica e da imposição da ideologia de mercado, que pensa apenas no lucro para poucos, em detrimento da necessidade constitucional de se garantir os direitos fundamentais à todos os seres humanos.

Enfim, somente uma bioética inclusiva, interdisciplinar, politizada e interventiva, poderá se comprometer com a criação de novas relações de poder, e assim, recusar a violência, a desigualdade e a exclusão social, acabando por fortalecer a democracia e aprimorar a cidadania, de modo a funcionar como uma 'ponte para o futuro', nos dizeres de Potter, onde um outro mundo possa ser vislumbrado, no sentido de garantir qualidade de vida para todos, sem distinção de qualquer espécie. 
Trata-se de uma bioética crítica, plural e interventiva, que funcione como um 'filtro' nas tomadas de decisões para que os Estados jamais se permitam negar as liberdades e as autonomias das pessoas, mutilando-as nas suas humanidades, na medida em que se prestam a impedir, inclusive, que elas exercitem os seus direitos ao inconformismo e a resistência.

Por fim, a necessidade da bioética ampliar, ainda mais, os seus limites conceituais, configurando-se como uma disciplina atenta à realidade mesma dos cidadãos, parece ser importante, principalmente, para que ela própria, como ética da vida, jamais se constitua como uma área de saber emudecida por sua própria inércia e, por conta disso, desvinculada dos cotidianos das pessoas concretas e preocupada apenas em nutrir os espaços vazios e silenciosos deixados pelo enfraquecimento do poder e pelo consequente fortalecimento da violência.

\section{Referências}

ATLAS DA VIOLÊNCIA (IPEA). Instituto de Pesquisa Econômica Aplicada; Fórum Brasileiro de Segurança Pública. (Orgs.), Brasília: Rio de Janeiro: São Paulo: Instituto de Pesquisa Econômica Aplicada; Fórum Brasileiro de Segurança Pública, 2019. Disponível em: http://www.ipea.gov.br Último acesso em 20/07/2019. ALMEIDA, A.M.O. et al. Violência, exclusão social e desenvolvimento humano - Estudo em representações sociais. Brasilia. Editora UnB, 2006.

ARENDT, H. Adignidade da política - Ensaios e Conferências. Antônio Abranches(Org,)

Tradução Helena Martins e outros. Rio de Janeiro: Relume-Dumará, 1993.

ARENDT, H. Sobre a Violência: Rio de Janeiro: Civilização Brasileira, 2009a

ARENDT, H. A Condição Humana, 10 ed. - Rio de Janeiro, Forense Universitária, 1981; 2009b.

ARENDT, H. Origens do totalitarismo, SP, Companhia das Letras, 2012

ARENDT, H. Eichman em Jerusalém: um Relato sobre a Banalidade do Mal, SP, Companhia das Letras, 1999.

ARENDT, H. Crises da República. Tradução José Volkmann. 3 ed. São Paulo: Perpectiva, 2015

BARCHIFONTAINE, C.P. de \& PESSINI, L. Bioética e Saúde. 2ed. Revista e Ampliada. São Paulo: Centro São Camilo de Desenvolvimento em Administração em Saúde, 1989.

BRASIL. Constituição da República Federativa do Brasil, Brasília,1988. DF, Senado.http://www.senado.gov.br/legislacao/const/con1988/con198805.10.1988/ art_225.shtm Acesso em Julho de 2019. 
CASTRO, J. Geografia da fome : o dilema brasileiro : pão ou aço. Rio de Janeiro : Edições Antares, 1984.

DARTIGUES, A. O que é Fenomenologia? Tradução de Maria José J.G. de Almeida. 7 Edição. Centauro Editora, 1992.

COSTA, S. \& DINIZ, D. Bioética - Ensaios. Letras Livres: Brasília, 2001

FORTES, Paulo Antônio de Carvalho \& ZOBOLI, Elma Lourdes Campos Pavone (org.)Bioética e saúde pública.São Paulo: Edições Loyola, 2003.

FOUCAULT, M. Microfísica do Poder. $16^{a}$. ed. Tradução de Roberto Machado; Rio de Janeiro: Edições Graal, 2001a

FOUCAULT, M. Vigiar e punir. Nascimento da prisão. $24^{a}$. ed. Tradução Raquel Ramalhete. Petrópolis:Vozes, 2001b.

FOUCAULT, M. O sujeito e o poder. In: DREYFUS, Hubert L. e RABINOW, Paul. Michel Foucault, uma trajetória filosófica: para além do estruturalismo e da hermenêutica. Rio de Janeiro: Forense Universitária, 1995.

GARRAFA, V. KOTTOW, M. \& SAADA, A.(Orgs.) Bases Conceituais Da Bioética Enfoque Latino Americano. Global Editora. 1. ed. , 2006

GARRAFA, V. \& PESSINI, L. (Orgs.). Bioética: poder e injustiça. São Paulo: Loyola, 2003.

GARRAFA, V. Da bioética de princípios a uma bioética interventiva. Bioética 2005a; 13(1):125-134.

GARRAFA, V. Inclusão social no contexto político da bioética. Revista Brasileira de Bioética 1(2):122-132. 2005b.

GIOVANELLA, L.; ESCOREL, S. \& LOBATO, L.V.C. et al. (org.). Políticas e Sistema de Saúde no Brasil. 2 Edição Revista e Ampliada. Rio de Janeiro: Editora FIOCRUZ, 2012.

HEIDEGGER, M. GA 20 - Prolegómenos para una historia del concepto de tiempo. Madrid: Alianza Editorial, 2007.

HEIDEGGER, M. Heidegger (Pensadores). São Paulo: Abril Cultural, 1999.

HEIDEGGER, M. Ser e Tempo. Petrópolis, RJ: Vozes; Bragança Paulista(SP). Editora Universitária São Francisco, 2015.

HUSSERL, E. Husserl. (Pensadores). São Paulo: Abril Cultural, 2005.

MERLEAU- PONTY, M. Fenomenologia da Percepção. Tradução Carlos Alberto Ribeiro de Moura. 2 Ed. São Paulo: Martins Fontes, 1999.

NEVES M.C.P. Bioética ou bioéticas. In: Neves MCP \& Lima M (coords). Bioética ou bioéticas na evolução das sociedades. Coimbra: Gráfica de Coimbra, 2005. p. 285-308.

OLIVEIRA, A.A.S. Bioética e Direitos Humanos - Prefacio de Volnei Garrafa - Edições Loyola: São Paulo. Brasil, 2011. 
PORTO D. \& GARRAFA V. Bioética de intervenção: considerações sobre a economia de mercado. Revista Bioética. 2005; 13(1): 111-23.

POTTER, V. R. Bioética- Ponte para o futuro. São Paulo: Edições Loyola, 2016.

SOUKI, N. Hannah Arendt e a banalidade do mal. Belo Horizonte: Editora UFMG, 2006.

UNESCO. Declaração Universal sobre Bioética e Direitos Humanos. Tradução brasileira. Paris, Outubro, 2005.

Recebido: 25/07/2019. Aprovado: 07/10/2019. 